\title{
ENSINO MÉDIO NO RIO DE JANEIRO: COMO AVANÇAR EM CONTEXTO ADVERSO
}

\section{HIGH SCHOOL IN RIO DE JANEIRO: HOW TO MAKE WAY IN AN ADVERSE CONTEXT}

CANABRAVA, Bruna Werneck ${ }^{1}$

\begin{abstract}
Resumo
Nos últimos anos, testemunhamos a aprovação de medidas estruturantes para a educação no Brasil, notadamente a Base Nacional Comum Curricular e a Reforma do Ensino Médio. Na primeira parte do artigo, resgatamos o histórico e a conjuntura da construção dessas políticas. Na segunda parte, analisamos o contexto político do estado de Rio de Janeiro e identificamos oportunidades para setor progressistas intervirem e redirecionarem a implementação dessas políticas.
\end{abstract}

Palavras-chave: Ensino Médio; BNCC; Rio de Janeiro; Estado; políticas públicas

\begin{abstract}
In the last few years, we have witnessed the approval of structuring measures for Education in Brazil, notably the Common Core National Curriculum and the High School Reform. In the first part of the article, we retrieve the history that shaped these policies. We then analyze the political context for the implementation of such policies in the state of Rio de Janeiro, identifying opportunities for progressive sectors of society to intervene and redirect the implementation of these policies.
\end{abstract}

KeYwORDS: high school; Common Core National Curriculum; Rio de Janeiro; State; public policies

\section{INTRODUÇÃo}

Educar é construir o futuro. Nessa construção, há sempre esforços de preservação e de transformação. Logo, há diferentes visões sobre o que deve ser preservado ou transformado. Por isso, a educação tende a ser um terreno de disputas.

A Constituição de 1988 estabelece:

A educação, direito de todos e dever do Estado e da família, será promovida e incentivada com a colaboração da sociedade, visando ao pleno desenvolvimento da pessoa, seu preparo para o exercício da cidadania e sua qualificação para o trabalho.

\footnotetext{
${ }^{1}$ Fundação Centro de Ciências e Educação Superior à Distância do Estado do Rio de Janeiro (CECIERJ). Rio de Janeiro, RJ, Brasil. e-mail: werneckb@gmail.com
} 
DOI: $10.12957 /$ e-mosaicos.2020.46471

A redação afirma a missão dupla da educação: preparar a pessoa tanto para o exercício da cidadania (que requer a capacidade de reflexão sobre a realidade ao redor, em toda sua complexidade) quanto para a inserção no mercado de trabalho (inclusão necessária para garantir-lhe as condições materiais para uma vida segura e saudável). Ao pensar a educação como motor de desenvolvimento local, regional e nacional, também nos deparamos com essa função dupla, pois, enquanto sociedade, precisamos de jovens bem formados nessas duas dimensões: capazes tanto de participar das atividades produtivas quanto de governar ou, ao menos, escolher e avaliar governantes.

Se, por um lado, o texto constitucional deixa claro que a educação a que todos têm direito não se restringe a conteúdos programáticos, por outro, a responsabilidade por efetivar esse direito é também dividida entre Estado e família e a colaboração da sociedade. É nessa divisão de responsabilidades que surgem vários dos conflitos das políticas educacionais. Há quem defenda que a escola deve, sim, se restringir aos conteúdos, evitando qualquer tema que suscite questionamentos dos valores morais ou religiosos aprendidos em casa. Há quem defenda que a escola deve priorizar as chamadas competências e habilidades socioemocionais. Há quem defenda que a escola é sobretudo um espaço de convivência e participação.

Entendemos que, nos últimos anos, foram homologadas duas políticas estruturantes para a educação no Brasil: a Base Nacional Comum Curricular (BNCC) e a Reforma do Ensino Médio (REM) - Medida Provisória 746/2016, posteriormente convertida na Lei $13.415 / 2017$. Ambas essas medidas têm impacto no dia-a-dia das escolas, na formação de professores e na elaboração de materiais didáticos.

Na primeira parte deste artigo, analisaremos a conjuntura política da formulação dessas políticas - BNCC e REM. Em seguida, levantaremos questões relacionadas à implementação nas escolas, que tem o prazo para ocorrer até 2022, no contexto do estado do Rio de Janeiro. Por fim, faremos algumas propostas sobre como se utilizar deste momento de transformação nas escolas a fim de avançar um projeto de educação emancipadora.

\section{CONTEXTO POLÍTICO DA ELABORAÇÃo DA BNCC E DA REM}

Em 2014, Dilma Rousseff é reeleita presidente da república e estabelece "Brasil, Pátria Educadora" como lema de seu segundo mandato:

Nosso lema será "Brasil, Pátria Educadora". Trata-se de lema com duplo significado.

Ao bradarmos "Brasil, Pátria Educadora", estamos dizendo que a educação será a prioridade das prioridades, mas também que devemos buscar, em todas as ações do governo, um sentido formador, uma prática cidadã, um compromisso de ética e um sentimento republicano. 
DOI: $10.12957 / \mathrm{e}-\mathrm{mosaicos} .2020 .46471$

Só a educação liberta um povo e lhe abre as portas de um futuro próspero. (TV SENADO, 2015)

Esse é um trecho de seu discurso de posse, no Congresso Nacional, em $1^{\circ}$ de janeiro de 2015. Nele, Dilma leva a educação para além de um investimento em indivíduos; insere a pauta em um projeto de nação. Os anos seguintes, no entanto, foram anos de duras crises política e econômica ${ }^{3}$, que culminaram em seu impeachment. Desde 2015, em vez das ambições grandiosas estabelecidas no discurso de posse, testemunhamos recorrentes contingenciamentos e cortes orçamentários na Educação.

A opção por estabelecer uma base nacional de currículos é bastante controversa, não apenas no Brasil. Mesmo dentre os que apoiam a construção de uma base comum, há divergência quanto ao grau de detalhamento que ela deve explicitar, pois há um equilíbrio a se encontrar - entre um instrumento para aferir aprendizagem e o respeito às diferenças e particularidades locais ${ }^{4}$. Há de se reconhecer, no entanto, que, desde a Constituição Federal, existe a intenção de se estabelecer conteúdos mínimos, vide o artigo 210: "Serão fixados conteúdos mínimos para o ensino fundamental, de maneira a assegurar formação básica comum e respeito aos valores culturais e artísticos, nacionais e regionais". E o termo "base nacional comum" aparece, pela primeira vez, na Lei de Diretrizes e Bases (LDB), de 1996.

$\mathrm{O}$ assunto permanece dormente até 2010, quando o Conselho Nacional de Educação define Diretrizes Curriculares Nacionais Gerais para a Educação Básica - uma etapa ainda anterior à base. A partir das diretrizes, foram elaborados os Parâmetros Curriculares Nacionais e, em 2014, o Plano Nacional de Educação (PNE, Lei no. 13.004/2014) faz menção a uma base nacional comum como parte das estratégias para atingir quatro das metas ali estabelecidas.

No Conselho Nacional de Educação, o tema da BNCC passou a ser discutido em uma Comissão Bicameral, criada pela Portaria CNE/CP no 11/2014 e sob a presidência de César Callegari. E, em junho de 2015, o então Ministro da Educação, Renato Janine Ribeiro, institui a Comissão de Especialistas para a Elaboração da Proposta da Base Nacional Comum Curricular, na Portaria no. 592 do MEC.

Já em setembro do mesmo ano, o MEC abre uma consulta pública, utilizando uma plataforma online, sobre a primeira versão da BNCC. As respostas foram compiladas por uma equipe da Universidade de Brasília e encaminhadas para uma equipe de redatores. Em maio de 2016, sai a segunda versão do documento e uma

\footnotetext{
2 TV SENADO. Posse Presidencial - Em sessão solene do Congresso, Dilma e Temer tomam posse. 10 jan. 2015. Disponível em: https://www.youtube.com/watch?v=s6sHeKn6QB0 . Acesso em: 7 jul. 2019. ${ }^{3}$ Há extensa literatura dedicada a analisar a crise institucional em que o Brasil se encontra, ainda hoje, em 2019. Não cabe aqui entrarmos nesse debate. Apenas constatamos que era um período turbulento da política nacional, como contexto para os acontecimentos no campo da educação no país.

${ }^{4}$ Para compreender um pouco mais dos argumentos daqueles que discordam da necessidade de uma base nacional comum, recomendamos a leitura de MACEDO, 2015.
} 
segunda abertura para contribuições do público: ao longo dos três meses seguintes, Undime $^{5}$ e Consed ${ }^{6}$ organizam $^{7}$ seminários estaduais ${ }^{8}$, dos quais participam, no total, mais de 9 mil pessoas, entre professores, gestores e alunos. Em setembro, as duas entidades entregam ao MEC um relatório com as contribuições feitas nos seminários a fim de que elas informem as mudanças para a redação da terceira versão da BNCC.

Vale lembrar que maio de 2016 é quando a Dilma é afastada da presidência, em decorrência de um processo de impeachment, que se conclui em agosto. Ou seja, o relatório foi entregue ao Ministério sob a gestão de Mendonça Filho, do governo Temer.

Neste meio tempo, em julho, o MEC - já sob Mendonça Filho, enquanto Temer era presidente interino - publica a portaria no. $790 / 2016$, que institui um único comitê gestor para duas missões distintas: finalizar a proposta de redação da BNCC e propor subsídios para a reforma do Ensino Médio. Essa portaria representa um claro redirecionamento das políticas: introduz o assunto de uma reforma do Ensino Médio, já estabelecendo que haveria diferentes percursos de formação, que até então não estava na pauta da discussão pública. É também nessa portaria que, pela primeira vez, tamanho destaque é dado às habilidades e que elas também estejam atreladas a anos específicos de ensino: "A versão da BNCC, a ser encaminhada ao Conselho Nacional de Educação - CNE, deverá definir o conjunto de conhecimentos e habilidades que os alunos devem adquirir e desenvolver em cada etapa de ensino e em cada ano de escolaridade." Sobre a inclusão das chamadas habilidades socioemocionais, nos referimos a Freitas (2014, p. 1107):

a matriz formativa proposta é restrita à dimensão do cognitivo. Cientes de sua limitação, camuflam todas as demais dimensões da formação sob o título de "habilidades socioemocionais" e, com isso, reduzem as outras dimensões a um conjunto de comportamentos novamente adaptativos.

Apenas dois meses depois da portaria 790/2016, o presidente Michel Temer publica a chamada "Reforma do Ensino Médio", se utilizando do instrumento da medida provisória (número 746/2016), e que foi, posteriormente, transformada na lei número 13.415/2017. O atravessamento do processo de construção da base pela reforma do Ensino Médio tem impactos profundos na redação final da BNCC. Na terceira versão do documento, publicada em abril de 2017, aponta num caminho bastante distinto do que vinha sendo traçado até então: a educação básica já não é mais tratada como um

\footnotetext{
${ }^{5}$ União Nacional dos Dirigentes Municipais de Educação

${ }^{6}$ Conselho Nacional de Secretários de Educação, que reúne as secretarias de estado e do Distrito Federal.

${ }^{7}$ Não sabemos se, nesta etapa, a comissão de 116 membros ainda estava envolvida na construção do documento. Não temos clareza sobre qual foi a real contribuição desta comissão, já que ela não é mencionada novamente, após a sua constituição.

8 Os relatórios das discussões em cada estado podem ser encontrados na página web http://historiadabncc.mec.gov.br/\#/site/relatorios
} 
DOI: $10.12957 / \mathrm{e}-\mathrm{mosaicos} .2020 .46471$

todo, pois constam no documento apenas os conteúdos relativos à educação infantil e o ensino fundamental, e o ensino médio é excluído. Além disso, nota-se o aumento do grau de especificação para cada disciplina em cada ano letivo.

Seguiu-se então mais uma etapa de consultas públicas - desta vez, organizadas pelo Conselho Nacional de Educação - que instruiu o parecer do CNE e finalmente levou a sua homologação em dezembro 2017.

A proposta elaborada para o Ensino Médio a partir da reforma aprovada em 2017 representa uma tal ruptura que não temos aqui tempo ou espaço para analisála com a devida atenção. Nos limitamos, então, a registrar o tempo recorde de produção da nova versão da BNCC do Ensino Médio: sua primeira versão foi apresentada em abril de 2018 e ela foi homologada em dezembro do mesmo ano. 0 curtíssimo prazo disponível para a discussão do projeto e contribuição da sociedade foi alvo de muitas críticas e levou à renúncia de César Callegari da posição de presidente da comissão bicameral do CNE:

De todo modo, já temos uma BNCC. Incompleta e certamente imperfeita, é verdade. [...]

Como sabem, nunca deixei de ter minhas próprias posições e convicções, como também minhas dúvidas e incertezas. Todavia, na presidência de um colegiado tão qualificado e plural como é a Comissão da BNCC, não poucas vezes preferi silenciar para propiciar as falas e as escutas, conciliar quando o impulso era tomar partido e disputar, insistir e animar mesmo quando pressões maiores tentavam obstruir ou desqualificar o trabalho. A presidência de uma Comissão como a nossa requer conduta firme, sensível, imparcial e democrática. Assim, com a participação de todos e a indispensável colaboração da equipe técnica do $\mathrm{CNE}$, avançamos.

No entanto, o quadro agora é outro. Temos pela frente a BNCC do ensino médio elaborada pelo MEC. Sobre ela, tenho severas críticas que considero honesto explicitar e ponderações que julgo necessário. [...]

Ao defender essas posições e essas propostas perante o nosso colegiado e perante a sociedade, entendo não ser mais adequada a minha permanência à frente da Comissão Bicameral da BNCC. (CALLEGARI, 2018) ${ }^{9}$

Ao longo de nossa pesquisa sobre construção da BNCC (CANABRAVA, 2019), notamos a ausência de uma participação mais ativa das organizações tradicionalmente ligadas à pauta da educação pública - muitas das quais têm a prerrogativa de indicar membros ao CNE, como a Associação Nacional de Pós-Graduação e Pesquisa em

\footnotetext{
${ }^{9}$ CALLEGARI, César. Carta aos conselheiros do Conselho Nacional de Educação - César Callegari renuncia à presidência da comissão da BNCC. 29 jun. 2018. Disponível em: http://www.epsjv.fiocruz.br/carta-aos-conselheiros-do-conselho-nacional-de-educacao-cesar-callegarirenuncia-a-presidencia-da. Acesso em: 14 jan. 2019
} 
DOI: $10.12957 / \mathrm{e}-\mathrm{mosaicos} .2020 .46471$

Educação (ANPEd), Associação Nacional pela Formação dos Profissionais da Educação (Anfope), Associação Nacional de Política e Administração da Educação (Anpae), Confederação Nacional dos Trabalhadores em Educação (CNTE) assim como os sindicatos de professores. Tivemos a oportunidade de entrevistar Cesar Callegari que, em entrevista, relatou:

Nós tivemos pouquíssima contribuição. Todo 0 acervo de conhecimento acumulado nas universidades públicas do Brasil - e são muitos desses conhecimentos inclusive bem aplicados... Quem é que produz livros didáticos no Brasil ou ao menos quem avalia para fins da seleção do Programa Nacional do livro Didático (PNLD), que põe na mão das escolas 160 milhões de livros por ano? São professores das Universidades Públicas. Há vários centros da maior relevância de pesquisas e pesquisas aplicadas na área da Educação Básica. Todos ficaram fora. Embora chamados, não participaram das audiências públicas [organizadas pelo $\mathrm{CNE}$, já em 2017], não participaram das conversas específicas que nós promovemos. Tem coisas que acabaram saindo e não precisavam ser assim. (Callegari, 2019) ${ }^{10}$

Embora tenham participado das reuniões iniciais, nas quais expuseram seus pontos de vista e participaram das negociações, para o entrevistado, o ponto de inflexão foi a derrubada do governo Dilma:

[Estávamos no contexto de] a assunção ao poder de um governo amplamente considerado ilegítimo e que deveria ser combatido politicamente. Então qualquer iniciativa - mesmo que tivesse origem, como foi a base, lá atrás, em outro contexto - ficava muito contaminada porque era uma ação que estava sendo desenvolvida pelo que estava sendo chamado de governo golpista. E esse era o motivo, também, pelo qual muitas dessas organizações acabaram não concordando em participar de nada que pudesse ser de interesse do governo Temer. (CALLEGARI, 2019) ${ }^{11}$

Justamente por ter sua legitimidade questionada, Temer tinha urgência em apresentar soluções para a sociedade. Enquanto os grupos mencionados acima se recusaram a participar do processo, no outro campo enxergou-se uma oportunidade de apresentar seus planos fechados a um governo demandante de medidas prontas para aprovação.

A mudança de governo teve então um efeito duplo: afastou as entidades com uma visão antagônica sobre o que deveria ser a base e abriu espaço para que os grupos ligados ao chamado terceiro setor passassem a atuar não apenas nos processos abertos à contribuição social, mas também dentro do próprio ministério, fornecendo recursos, apoio e indicação de quadros:

${ }^{10}$ CALLEGARI, César. Entrevista à autora. São Paulo, 2019.

${ }^{11}$ CALLEGARI, César. Entrevista à autora. São Paulo, 2019. 
DOI: $10.12957 / \mathrm{e}-\mathrm{mosaicos} .2020 .46471$

É importante destacar que com a vinda da nova equipe do Ministério da Educação [...], eles se serviram muito de apoios externos dessas instituições que proporcionaram contratação de especialistas, produção de pareceres, de seminários, encontros, materiais, uma quantidade enorme de coisas relacionadas à base que o ministério teria mesmo dificuldade de encontrar, só que nesse caso não ficaram resignados de ter de aceitar esse tipo de ajuda. Quiseram, eram demandantes desse tipo de contribuição dessas organizações. Eu vejo que a própria fragilidade do aparelho do Estado, de um lado, e de outro lado, uma decisão política de várias organizações do campo da educação brasileira [Anped, Anfop, Anpae, CNTE e seus sindicatos] de se retirarem do processo abriu um espaço enorme para a participação dessas entidades do terceiro setor que foram sendo muito influentes. (CALLEGARI, 2019) ${ }^{12}$

\section{IMPLEMENTAÇÃO DA BNCC E REM NO CONTEXTO DO ESTADO DO RIO DE JANEIRO}

O prazo para a reformulação dos currículos de Ensino Médio, já alinhados à BNCC e seus itinerários formativos, é 2022. No estado do Rio de Janeiro, isso significa que tal reformulação se dará sob o governo de Wilson Witzel, do Partido Social Cristão (PSC). Witzel, que foi fuzileiro naval e juiz federal antes de entrar para a política, foi eleito com amplo apoio de igrejas evangélicas e um discurso de combate à corrupção e à violência urbana, no contexto da alta popularidade de Jair Bolsonaro. tais como:

Para a pasta da educação, em seu programa de governo, encontramos pontos

Criação de uma rede de escolas estaduais militares, em parceria com as Forças Armadas e PMERJ, com o objetivo de replicar modelos como da Escola Naval, EpCAr e Colégio Militar à nível estadual;

No longo prazo, especialização de todas as escolas estaduais em (a) FAETECS $^{13}$; (b) profissionalizantes e (c) militares, garantindo uma rede $100 \%$ em período integral e com escolha dos pais; (PLANO, 2018) ${ }^{14}$

Setores progressistas se deparam, então, com o mesmo dilema que esteve posto à época da elaboração da BNCC: diante de um governo tido como hostil a seus ideais, escolher entre buscar participar e influenciar a construção de políticas educacionais ou se limitar a uma posição de denúncia e crítica.

Nossa posição é a de que devemos sempre tentar influir nos rumos da educação. Sendo assim, elencamos a seguir alguns aspectos de documentos já

\footnotetext{
12 CALLEGARI, César. Entrevista à autora. São Paulo, 2019.

${ }^{13}$ Rede de escolas técnicas estaduais. Essas escolas não ficam sob o controle da Secretaria de Estado de Educação (SEEDUC), mas da Secretaria de Estado de Ciência, Tecnologia e Inovação (SECTI).

14 Plano de governo Wilson Witzel. 2018. Disponível em: http://divulgacandcontas.tse.jus.br/ candidaturas/oficial/2018/BR/RJ/2022802018/190000612301/proposta 1534218285632.pdf. Acesso em: 04. nov. 2019
} 
DOI: $10.12957 /$ e-mosaicos.2020.46471

existentes que servem de pontos de partida para o redirecionamento dessas políticas (adequação dos currículos à BNCC e à REM) para uma educação emancipadora:

1. Previsão, no programa de governo de Witzel, de parceria entre a Seeduc e as universidades estaduais para a formação continuada de professores

O ponto 12 da seção sobre educação, no programa de governo apresentado por Witzel, à época das eleições, diz:

Implantar programa de formação continuada de professores, com parceria entre a Secretaria de Estado de Educação e Universidades Estaduais, capacitando-os para o melhor desenvolvimento de suas atividades educacionais; (PLANO, 2018) ${ }^{15}$

Temos, nos últimos anos, visto crescer, em todo o Brasil, a tendência de contratação de empresas privadas ou entidades do terceiro setor para a formação de professores da rede pública. Devemos nos utilizar desta abertura para frear esta tendência. Devemos estruturar, nas universidades estaduais, programas de extensão e cursos de pós-graduação, tais como mestrados profissionais, voltados para a prática profissional de professores.

A universidade pública tem o potencial de se tornar um local de encontro entre pesquisadores e professores, gerando ganhos para ambas as partes. Por um lado, os professores têm a oportunidade de trocar experiências entre si, refletir coletivamente sobre as próprias práticas e se atualizar; por outro, os pesquisadores têm a oportunidade de, a partir de um convívio com os professores, acompanhar mais de perto as questões que surgem no cotidiano escolar. Numa época em que sofre muitos ataques, a universidade, como instituição, ainda se beneficia de uma oportunidade de evidenciar seu valor para a sociedade como um todo.

2. Programa de Apoio à Implementação da BNCC (ProBNCC), do governo federal

O governo federal lançou, em 2018, o "Programa de Apoio à Implementação da BNCC - ProBNCC" (Portaria MEC no 331, de 5 de abril de 2018), com o objetivo de apoiar as secretarias de educação dos entes subnacionais na revisão ou elaboração e implementação de currículos alinhados à BNCC. Em 3 de abril de 2019, o programa foi revisado para comtemplar aspectos específicos da BNCC do Ensino Médio, através da na Portaria MEC no 756.

15 Plano de governo Wilson Witzel. 2018. Disponível em: http://divulgacandcontas.tse.jus.br/ candidaturas/oficial/2018/BR/RJ/2022802018/190000612301/proposta 1534218285632.pdf. Acesso em: 04. nov. 2019 
DOI: $10.12957 /$ e-mosaicos.2020.46471

De acordo com o documento "Programa de Apoio à Implementação da BNCC ProBNCC - Documento Orientador 2019":

Os principais desafios para os participantes do programa são, para o ciclo 2 de Educação Infantil e Ensino Fundamental, realizar formações continuadas de qualidade, atendendo às premissas definidas no Guia de Implementação da BNCC e com um regime de colaboração bem estabelecido. Para o ciclo 1, do Ensino Médio, os principais desafios são elaborar os itinerários formativos de forma interessante para os alunos e que a rede seja capaz de oferecer, e incluir nos currículos orientações aos professores de como ensinar aos alunos as competências gerais da BNCC de maneira prática. (MEC, 2019) ${ }^{16}$

O Rio de Janeiro é um dos estados que aderiu ao programa (MOVIMENTO PELA BASE, 2019) e precisamos estar atentos aos 57 profissionais que compõem a Equipe Estadual de currículo daqui. No âmbito do programa, é esta a equipe responsável por redesenhar os currículos e formar os profissionais da rede para a implementação dos novos currículos. Portanto, mais do que o governador, secretários de educação, subsecretários, parlamentares ou membros dos conselhos de educação, são esses os nossos principais interlocutores, nessa questão.

Quadro: Equipe Estadual de currículo, ProBNCC

\begin{tabular}{lll}
\hline Perfil & Etapa de ensino & Quantidade por estado \\
\hline Coordenadores estaduais & $\begin{array}{l}\text { Educação infantil, } \\
\text { Ensino fundamental e Ensino } \\
\text { médio }\end{array}$ & $\begin{array}{l}\text { 2, indicados pelo Consed e pela } \\
\text { Undime }\end{array}$ \\
\hline $\begin{array}{l}\text { Articulador de regime de } \\
\text { colaboração }\end{array}$ & $\begin{array}{l}\text { Educação infantil e } \\
\text { Ensino fundamental }\end{array}$ & 1, indicado pela Undime \\
\hline Coordenadores de etapa & $\begin{array}{l}\text { Educação infantil, } \\
\text { Ensino fundamental e Ensino } \\
\text { médio }\end{array}$ & $\begin{array}{l}4 \text { (1 para EI, 1 para anos } \\
\text { iniciais do EF, 1 para anos } \\
\text { finais do EF e 1 para EM) }\end{array}$ \\
\hline Redatores formadores & $\begin{array}{l}\text { Educação infantil, } \\
\text { Ensino fundamental e Ensino } \\
\text { médio }\end{array}$ & $\begin{array}{l}40 \text { (22 para EI e EF e 18 para } \\
\text { EM) }\end{array}$ \\
\hline $\begin{array}{l}\text { Articuladores de Conselho de } \\
\text { Educação }\end{array}$ & $\begin{array}{l}\text { Educação infantil, } \\
\text { Ensino fundamental e Ensino } \\
\text { médio }\end{array}$ & $\begin{array}{l}3,2 \text { indicados pelo FNCEE } \\
\text { indicado pela Uncme } 18\end{array}$ \\
\hline Coordenador de Área & Ensino médio & 4,1 por área de conhecimento
\end{tabular}

16 MEC. Programa de Apoio à Implementação da BNCC - ProBNCC - Documento Orientador 2019. Disponível em: http://basenacionalcomum.mec.gov.br/images/implementacao/ doc orientador probncc 2019.pdf . Acesso em: 03 nov. 2019.

${ }_{17}$ Fórum Nacional dos Conselhos Estaduais de Educação

18 União dos Conselhos Municipais de Educação 
DOI: $10.12957 /$ e-mosaicos.2020.46471

Articuladores de itinerários Ensino médio

2, 1 para as áreas de conhecimento, 1 para formação técnica/ profissionalizante

Articulador entre etapas

Ensino médio

1, indicado pela Undime

Fonte: Elaboração própria, adaptado do documento orientador Pro-BNCC 2019

\section{Desenvolvimento de competências, na BNCC}

Ao longo dos documentos finais da BNCC (tanto no documento da educação infantil e ensino fundamental, quanto no documento relativo ao ensino médio), as habilidades parecem de forma atomizada, específicas para cada nível educacional. No entanto, as competências de educação básica, como redigidas no capítulo introdutório, dizem respeito as diferentes dimensões do ser humano, como, por exemplo:

Valorizar e utilizar os conhecimentos historicamente construídos sobre o mundo físico, social, cultural e digital para entender e explicar a realidade, continuar aprendendo e colaborar para a construção de uma sociedade justa, democrática e inclusiva.

Exercitar a curiosidade intelectual e recorrer à abordagem própria das ciências, incluindo a investigação, a reflexão, a análise crítica, a imaginação e a criatividade, para investigar causas, elaborar e testar hipóteses, formular e resolver problemas e criar soluções (inclusive tecnológicas) com base nos conhecimentos das diferentes áreas.

Valorizar e fruir as diversas manifestações artísticas e culturais, das locais às mundiais, e também participar de práticas diversificadas da produção artístico-cultural. (MEC) ${ }^{19}$

Dentro da proposta de formação de professores com vistas a desenvolver essas competências nos alunos, uma abordagem progressista deve ser capaz de alinhavar novamente essas habilidades atomizadas em uma educação integral. Além disso, podemos utilizar esse aspecto da BNCC para propor atividades que conectem a escola com outros setores da sociedade; por exemplo, requerer transporte para levar os estudantes a espaços culturais e de ciência.

4. Previsão de aumento da carga horária, na Reforma do Ensino Médio, e proposta de aumento de investimentos em educação, no programa de governo de Witzel

A educação em tempo integral e maior investimento na educação são bandeiras do campo progressista há muito tempo. Devemos ter clareza de nossas prioridades

\footnotetext{
${ }^{19}$ MEC. Base Nacional Comum Curricular. Disponível em: http://basenacionalcomum.mec.gov.br/images/BNCC EI EF 110518 versaofinal site.pdf Acesso em: 3 nov. 2019.
} 
DOI: $10.12957 / \mathrm{e}-\mathrm{mosaicos} .2020 .46471$

em termos de investimentos nas escolas e argumentos que as sustentem, caso haja, de fato, uma disponibilidade de aportes financeiros por parte do governo do estado.

Ademais, devemos ser capazes de estruturar nossos ideais em propostas concretas sobre como utilizar o "tempo extra", com linguagem acessível e convincente aos olhos de nossos governantes atuais, para aproveitar este momento em que existe uma boa-vontade para a ampliação da jornada escolar.

5. Utilização de parte da carga horária na modalidade a distância (EAD), na Reforma do Ensino Médio

Esse foi um dos pontos que mais sofreu críticas, na proposta de Reforma do Ensino Médio. Compreensível, se observamos que o que vem sendo praticado como modelo de educação a distância é uma reprodução do que há de pior na educação presencial: aulas expositivas - mesmo que em vídeos bem produzidos - e questionários múltipla escolha - mesmo que disfarçados de jogos.

É importante destacar que o que está previsto na Lei $13.415 / 17$ é a alocação de até $20 \%$ da carga horária para atividades a distância, ao mesmo tempo em que está prevista a ampliação da jornada escolar de 800 para 1000 horas por ano. Ou seja, a implementação desta política não implicaria em uma redução do tempo presencial nas escolas.

Quando mal utilizadas, as tecnologias informacionais podem ser alienantes, deixando o aluno em uma trajetória personalizada, porém solitária. Os recursos de EAD são enriquecedores para o estudante quando são capazes de encurtar distâncias e aproximá-lo de outras realidades. Além disso, as novas tecnologias oferecem aos alunos ferramentas que permitem diferentes formas de se expressar: foto, vídeo, infográfico, textos não lineares com hiperlinks etc. Em contextos de enormes carências e vulnerabilidades como temos aqui no estado, recursos de EAD têm o potencial de ampliar horizontes e proporcionar trocas de experiências com pessoas que vivem em lugares diferentes. Um exemplo disso seria a promoção de atividades on-line conjuntas entre escolas de regiões diferentes do estado.

\section{CONSIDERAÇõES FINAIS}

Em 2019, vivemos o que muitos consideram "uma onda conservadora". No contexto do estado do Rio de Janeiro, temos governantes que se declaram conservadores em ambas as esferas estadual e federal. Nos restringirmos a uma posição de denúncia e crítica pura nos relega à posição de meros observadores de um processo que ainda está em curso e, portanto, aberto para modificações. Mesmo em um contexto politicamente adverso, ou até porque o contexto é adverso, não podemos deixar de tentar avançar nossas ideias sobre educação. Isso requer que adaptemos a 
DOI: $10.12957 /$ e-mosaicos.2020.46471

linguagem do que advogamos para conseguirmos nos comunicar com quem detém o poder decisório.

Os próximos três anos serão decisivos para o futuro da educação, pois além da reformulação dos currículos, haverá implicações para a formação continuada de professores e elaboração de materiais didáticos. Espero, neste artigo, ter contribuído, identificando oportunidades e propondo estratégias para que sejamos capazes de intervir nos rumos da educação pública em nosso estado.

\section{REFERÊNCIAS}

CALLEGARI, César. Carta aos conselheiros do Conselho Nacional de Educação - César Callegari renuncia à presidência da comissão da BNCC. 29 jun. 2018. Disponível em: http://www.epsjv.fiocruz.br/carta-aos-conselheiros-do-conselho-nacional-deeducacao-cesar-callegari-renuncia-a-presidencia-da. Acesso em: 14 jan. 2019

CALLEGARI, César. Entrevista à autora. São Paulo, 2019.

CANABRAVA, Bruna Werneck. O projeto Lemann e a educação brasileira: da filantropia à cooptação?. Dissertação de Mestrado. Niterói: Universidade Federal Fluminense, 2019.

FREITAS, Luiz Carlos de. Os reformadores empresariais da educação e a disputa pelo controle do processo pedagógico na escola. In: Educação \& Sociedade vol.35 no.129 Campinas Oct./Dec. 2014. Disponível em:

https://www.scielo.br/pdf/es/v35n129/0101-7330-es-35-129-01085.pdf Acesso em: 31 mai. 2019

MEC. Base Nacional Comum Curricular. Disponível em:

http://basenacionalcomum.mec.gov.br/images/BNCC EI EF 110518 versaofinal site .pdf Acesso em: 3 nov. 2019.

- Programa de Apoio à Implementação da BNCC - ProBNCC - Documento Orientador 2019. Disponível em: http://basenacionalcomum.mec.gov.br/ images/implementacao/doc orientador probncc 2019.pdf Acesso em: 03 nov. 2019.

MOVIMENTO PELA BASE. MEC realiza encontros formativos com equipes ProBNCC de todo país. 28 ago. 2019. Disponível em:

http://movimentopelabase.org.br/acontece/mec-realiza-encontros-formativos-comequipes-probncc-de-todo-pais/. Acesso em: 03. nov. 2019.

PLANO de governo Wilson Witzel. 2018. Disponível em:

http://divulgacandcontas.tse.jus.br/candidaturas/oficial/2018/BR/RJ/2022802018/190 000612301/proposta 1534218285632.pdf. Acesso em: 04. nov. 2019 
DOI: $10.12957 /$ e-mosaicos.2020.46471

TITTON, Maria Beatriz Pauperio. Caminhos da Educação Integral no Brasil: direito a outros tempos e espaços educativos. Educ. rev., Curitiba, n. 45, p. 295-300, set. 2012. Disponível em: http://www.scielo.br/scielo.php?script=sci arttext\&pid =S0104-40602012000300019\&lng=en\&nrm=iso. Acesso em: 05 nov. 2019.

TV SENADO. Posse Presidencial - Em sessão solene do Congresso, Dilma e Temer tomam posse. $1^{0}$ jan. 2015. Disponível em:

https://www.youtube.com/watch?v=s6sHeKn6QB0. Acesso em: 7 jul. 2019.

Recebido em 04 de novembro de 2019

Aceito em 11 de abril de 2020

coautor(es), com o direito de primeira publicação cedido à e-Mosaicos.

Os artigos publicados são de acesso público, de uso gratuito, com atribuição de autoria obrigatória, para aplicações de finalidade educacional e não-comercial, de acordo com o modelo de licenciamento Creative Commons adotado pela revista. 